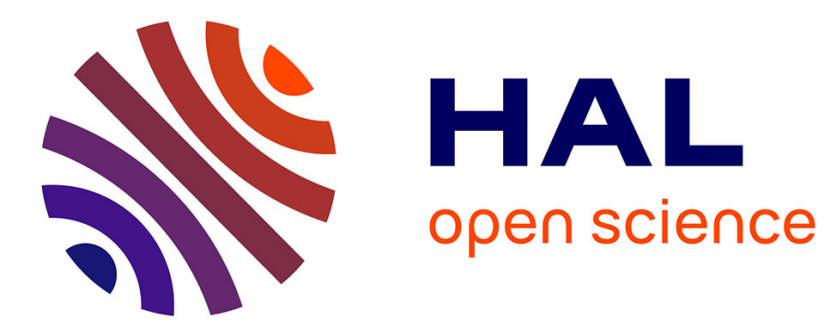

\title{
In-vivo analysis of thoracic mechanical response under belt loading: the role of Body Mass Index in thorax stiffness
}

David Poulard, François Bermond, Sabine Compigne, Karine Bruyere-Garnier

\section{- To cite this version:}

David Poulard, François Bermond, Sabine Compigne, Karine Bruyere-Garnier. In-vivo analysis of thoracic mechanical response under belt loading: the role of Body Mass Index in thorax stiffness. Journal of Biomechanics, 2013, 46 (5), pp. 883-889. 10.1016/j.jbiomech.2012.12.021 . hal-00919874

\section{HAL Id: hal-00919874 \\ https://hal.science/hal-00919874}

Submitted on 4 Nov 2019

HAL is a multi-disciplinary open access archive for the deposit and dissemination of scientific research documents, whether they are published or not. The documents may come from teaching and research institutions in France or abroad, or from public or private research centers.
L'archive ouverte pluridisciplinaire HAL, est destinée au dépôt et à la diffusion de documents scientifiques de niveau recherche, publiés ou non, émanant des établissements d'enseignement et de recherche français ou étrangers, des laboratoires publics ou privés. 


\section{In-vivo analysis of thoracic mechanical response under belt}

loading: the role of Body Mass Index in thorax stiffness

David Poulard $^{1 *}$, François Bermond $^{1}$, Sabine Compigne ${ }^{2}$, Karine Bruyère $^{1}$

${ }^{1}$ Université de Lyon, F-69622, Lyon; IFSTTAR, LBMC, UMR_T9406, F-69675, Bron ; Université Lyon 1, Villeurbanne, France.

${ }^{2}$ Toyota Motor Europe, Zaventem, Belgium.

"Corresponding author at: LBMC - Site Ifsttar Lyon-Bron, 25 Av. F. Mitterrand, Case 24, 69675 Bron Cedex, France. Tel.: +33 478656873; fax: +33 472376837. E-mail adress: david.poulard@ifsttar.fr.

Word count: 2777 words (Introduction through Acknowledgements). 


\section{ABSTRACT}

Thoracic injuries are a major cause of mortality in frontal collisions, especially for elderly and obese people. Car occupant individual characteristics like BMI are known to influence human vulnerability in crashes. In the present study, thoracic mechanical response of volunteers quantified by optical method was linked to individual characteristics. 13 relaxed volunteers of different anthropometries, genders and age were submitted to non-injurious sled tests $(4 \mathrm{~g}, 8$ $\mathrm{km} / \mathrm{h}$ ) with a sled buck representing the environment of a front passenger restrained by a 3point belt. A resulting shoulder belt force was computed using the external and internal shoulder belt loads and considering shoulder belt geometry. The mid sternal deflection was calculated as the distance variation between markers placed at mid-sternum and the $7^{\text {th }}$ vertebra spinous process of the subject. Force-deflection curves were constructed using resulting shoulder belt force and midsternal deflection. Average maximum chest compression was $7.9 \pm 2.3 \%$ and no significant difference was observed between overweight subjects $\left(\mathrm{BMI} \geq 25 \mathrm{~kg} / \mathrm{m}^{2}\right)$ and normal subject $\left(\mathrm{BMI}<25 \mathrm{~kg} / \mathrm{m}^{2}\right)$. The overweight subjects exhibited significantly greater resultant belt forces than normal subjects $(715 \pm 132 \mathrm{~N}$ vs. $527 \pm 111 \mathrm{~N}$, $\mathrm{p}<0.05)$, higher effective stiffness $(30.9 \pm 10.6 \mathrm{~N} / \mathrm{mm}$ vs. $19.6 \pm 8.9 \mathrm{~N} / \mathrm{mm}, \mathrm{p}<0.05)$ and lower dynamic stiffness $(42.7 \pm 8.71 \mathrm{~N} / \mathrm{mm}$ vs. $61.7 \pm 15.5 \mathrm{~N} / \mathrm{mm}, \mathrm{p}<0.05)$.

Keywords: Biomechanics, sled test, BMI, stereovision, thoracic stiffness, volunteer 


\section{Introduction}

Although significant improvements have been achieved in mitigating road traffic fatalities, frontal impacts play a predominant role in the frequency of road traffic fatalities as they account for up to $46 \%$ of the mortality (Klanner, 2001). Statistics show that in France thoracic injuries were the first cause of death among car occupants in frontal collisions and the main source of serious casualties of elderly occupants (Lafont and Laumon, 2003; Ndiaye and Chiron, 2009). Moreover, if we focus on moderate injuries sustained by the elderly population, rib and sternum fractures are mainly observed (Ndiaye and Chiron, 2009).

First studies on Post Mortem Human Surrogates (PMHS) focused on generating thoracic force-deflection corridors using a hub-impact test condition (Kroell C.K., 1971; Lobdell et al., 1973; Nahum A.M., 1975; Lau and Viano, 1986). These corridors were used in the development of frontal impact dummies. A statistical relationship was established between midsternal compression and thorax injury risk (Kroell C.K., 1971; Mertz et al., 1991). However, force-deflection corridors of the thorax were found to be strongly dependent on the load distribution (Kent et al., 2004), and particularly on the anatomical area that supports the load (Shaw et al., 2007). Moreover, thoracic mechanical response depends strongly on the geometrical characteristics of the ribcage and on its biological material properties (Kent et al., 2005; Gayzik et al., 2008). Authors agree that the deformation of the rib cage under an anteroposterior loading is divided into rib rotation relative to the vertebrae and sternum, and rib deflection (Kent et al., 2005). More accurately, it is assumed that according to the rib orientation, the applied force causes rib deformations and rotations at various degrees (Kent et al., 2005). Specifically, for an individual with a "vertical" rib cage, an applied anteroposterior load produces rotations of the rib joints and bone deformation whereas, for individual with a "horizontal" rib cage, the load force acts straight in the plane of the ribs and implies primarily bone deformation. A link was found between the initial rib slope and the 
amount of rotation and deformation (Vezin and Berthet, 2009). Thus, it seems that geometrical characteristics of the ribcage may predispose ribs to fracturing.

In addition, it was well established that tolerance of the human thorax under dynamic loading decreases as age increases (Ndiaye and Chiron, 2009; Kroell C.K., 1971; Zhou et al., 1996; Kent et al., 2005). Physiological phenomena of ageing could be described as the combination of mechanical and structural modifications associated with a decrease in chest deflection tolerance. The elastic modulus and the tensile strength of human bones decrease with age (Zhou et al., 1996). Similarly, a decrease in the tensile strength of hyaline rib cartilage and cortical thickness in the rib sections was observed (Takahashi and Frost, 1966; Yamada, 1970; Kemper et al., 2007). The age-related changes in thorax shape were also studied and authors assumed that the ribs became more horizontal with age and the slope of ribs in sagittal plane decreased with age (Oskvig, 1999; Kent et al., 2005; Gayzik et al., 2008). Yet, some authors also found a correlation between BMI and the thorax shape (Berthet et al., 2005; Gayzik et al., 2008). Body Mass Index (BMI) was associated with increased risk of mortality and increased risk of severe injury with a predominant occurrence for rib fractures and pulmonary contusions (Boulanger et al., 1992; Mock et al., 2002). Obese subjects were linked to unfavorable kinematics (greater head and pelvis excursions) and may be linked to higher chest compression (Forman et al., 2009). In the vast majority of developed countries, the prevalence of overweight and obesity in older adult population is very high (Gutierrez-Fisac et al., 2004). Thus, in order to study the variability of the population in age, anthropometry and for both genders, in vivo experiments seem necessary. Except early in-vivo experimental studies (Armstrong et al., 1968; Lobdell et al., 1973; Stalnaker et al., 1973) which brought knowledge on the human body tolerance, most of them were used to analyze the physiology influence on the body response to dynamic loading - muscle tone (Patrick, 1981; Backaitis and St-Laurent, 1986; Kemper et al., 2011)- or to assess the response of specific populations such as children 
for non-injurious levels (Sandoz et al., 2009; Arbogast et al., 2009a; Arbogast et al., 2009b). In the present paper, we present the analysis of thoracic mechanical response under belt loading of adults of various anthropometries and age subjected to a low deceleration pulse (Poulard et al., 2011). In particular, the influence of overweight $\left(\mathrm{BMI} \geq 25 \mathrm{~kg} / \mathrm{m}^{2}\right)$ on thoracic mechanical response will be assessed.

\section{Materials and methods}

This in vivo protocol was reviewed and approved by the French ethical committee Comité de Protection des Personnes Sud-Est II at Lyon in February 2011.

\section{Test device}

Ifsttar shock sled was set up with a standard sedan car environment of a front passenger restrained by a 3-point belt (Fig. 1). Posterior support consisted of a belt band tensed between the two backseat rods. Weight was added to the sled according to the weight of the subject (up to $110 \mathrm{~kg}$ ) in order to maintain a constant sled mass $(640 \mathrm{~kg})$. The propelling system of the sled was chosen to allow low impact velocities with a good repeatability in pulses and to limit the maximum impact speed; it was made of two rubber bands of diameter $20 \mathrm{~mm}$ mounted on each side of the sled.

\section{Deceleration pulse}

As described in Poulard et al. (2011), the deceleration pulse was chosen between 2 pulses measured on 2 public demonstrators and it was found similar to the one of a recent study (Arbogast et al., 2009a). The sled was pulled rearward by an electrical winch until reaching $165 \%$ of the two rubber bands' initial length so that an impact speed of $8 \mathrm{~km} / \mathrm{h}$ was reached. The deceleration system was obtained by laminating a polyurethane tube by a spear ended in an olive shape (hardness $95 \mathrm{SHA}, 46.5 \mathrm{~mm}$ diameter spear). The sled was stopped with a maximum deceleration of $4 \mathrm{~g}$ during $120 \mathrm{~ms}$.

Tested subjects 
13 volunteers were tested. They were between 19 and 65 years of age and consisted of both males and females. They were chosen on criteria of height based upon anthropometry charts (Jürgens et al., 1990) and various BMI. Volunteer characteristics are listed in Table 1.

For physiological issues, subjects with existing endocrine disorders, mediastinal pathologies, previous or current diseases of the head, neck, spine were excluded from the tests. Only volunteers over 40 years of age with no osteopenia or osteoporosis (total femoral and lumbar Tscore >-1) were included in sled testing experiments. Prior to the testing, a medical doctor conducted an examination of each subject to confirm eligibility.

Two sled tests were performed on each volunteer. For each test, they were asked to adopt a relaxed posture.

\section{Instrumentation}

The longitudinal deceleration of the sled was recorded by a sled-mounted uniaxial accelerometer. Three belt webbing load cells were installed: on the external end (FB3) and on the internal end (FB4) of the shoulder belt and on the external side of the lap belt. Maximum value of $\mathrm{FB} 3$ and $\mathrm{FB} 4$ are noted $\mathrm{FB} 3_{\max }$ and $\mathrm{FB} 4_{\max }$ respectively. Reaction forces were measured by four uniaxial load cells placed under each footrest and under the seat pan. Data were acquired at $20 \mathrm{kHz}$ during $5 \mathrm{~s}$ and filtered using CFC Butterworth filters according to the standard norm SAE J211.

\section{Stereovision}

Markers were placed on volunteers at anatomical landmarks:

- Spine: spinous processes of C7, T1, T7, and L4 and all along the spine,

- Torso : on left and right acromion and clavicles, jugular notch (JN), mid-sternum (MS), xiphoid process (XP) and all along the sternum. Additional landmarks were additionally placed $5 \mathrm{~cm}$ and $10 \mathrm{~cm}$ to the left and right side of chest and on the inferior contour of the ribcage. 
In addition, markers were placed on the sled in order to follow sled displacement.

Four high speed cameras were positioned around the sled for recording at $1000 \mathrm{fps}$ the position of markers placed on subjects and sled (Fig. 2). Time zero was given by a flash visible by all cameras and synchronised with the data acquisition system. After the tests, the scene was calibrated by using a calibration object and the three dimensional coordinates of the subject markers were computed using the Direct Linear Transformation method also called stereovision (Abdel-Aziz and Karara, 1971). Accuracy of the optical method was assessed in a previous study (Poulard et al., 2011). 3D trajectories were filtered at CFC-60 Butterworth. Anatomical landmarks were obstructed from view during some frames during the test, and thus, the $3 \mathrm{D}$ reconstruction by stereovision was not possible during these frames. Therefore the missing part of the trajectory was interpolated using other landmarks available at the same frame (see Appendices for more details).

\section{Data analysis}

The mid sternal deflection (D) was calculated as the distance variation between markers placed at mid-sternum and at 7 th vertebra spinous process of the subject. The initial zero of deflection was defined as the midsternal thickness measured after reaching $5 \%$ of the maximum value of external shoulder belt load (see midsternal thickness in Table 1). Midsternal compression $\mathrm{C}$ was defined as the ratio of the mid sternal deflection to the midsternal thickness. Maximum values of $\mathrm{D}$ and $\mathrm{C}$ are noted $\mathrm{D}_{\max }$ and $\mathrm{C}_{\max }$ respectively.

Resulting shoulder belt force (FRes) is defined as $F \operatorname{Res}=\sqrt{F B 3^{2}+F B 4^{2}-2 \times F B 3 \times F B 4 \times \cos (\pi-\alpha)}$ and Fig. 3 as a combination of the external shoulder belt load (FB3), the internal shoulder belt load (FB4) and the angle made by the belt $(\alpha)$ calculated using the extreme markers of the belt (Eickhoff et al., 2011). A timeinterpolation of FB3 and FB4 was performed for combining angles values and loads values. Maximum value of FRes is noted FRes $\max$. 
FRes is a $2 \mathrm{D}$ approximation of the $3 \mathrm{D}$ resulting belt force acting on the thorax. Nevertheless, the obtained FRes force vector is correctly aligned with the mid sternal deflection (D) vector (see Appendices for more details).

Force-deflection curves were built using FRes and mid sternal deflection D. Dynamic Stiffness (DS) was computed as the interpolated ratio of the resulting shoulder belt load force FRes over the midsternal deflection D before FRes max $_{\text {was }}$ reached. Effective Stiffness (ES) was computed from the ratio of FRes over D when $D_{\max }$ was reached (Kent et al., 2005; Sandoz et al., 2009). While DS represents the thorax behaviour during the beginning of the load, ES represents its behaviour without taking account of this part.

The statistical analysis was carried out with $\mathrm{R}$ software for Windows ver. 2.14.2. Numerical variables were given as average \pm standard deviation (SD). Groups were compared with permuted Student's t-test. Comparisons were considered as significant for $\mathrm{p}<0.05$.

\section{Results}

\section{Definition of an individual thoracic mechanical response}

Two sled tests were performed for each volunteer. The force-deflection responses obtained in these two tests were found significantly different. The results of the test for which the highest Dmax was measured, was only considered. Thoracic mechanical characteristics are synthetized in Table 2. The initial shoulder belt angle $\alpha$ is noted $\alpha$ ini.

\section{Seat belt loads}

Separate curves from overweight $\left(\mathrm{BMI} \geq 25 \mathrm{~kg} / \mathrm{m}^{2}, \mathrm{n}=5\right)$ and normal subjects $\left(\mathrm{BMI}<25 \mathrm{~kg} / \mathrm{m}^{2}\right.$, $\mathrm{n}=8$ ) for the external shoulder belt load FB3 and the resulting shoulder load FRes are shown in Fig. 4. At the beginning of the shock, $5 \%$ of FB3max was reached at $55 \pm 5 \mathrm{~ms}(\mathrm{n}=13)$. At an average time of $118 \pm 8 \mathrm{~ms}(\mathrm{n}=13)$, FB3 and FRes reached their peak. No significant difference $\left(\mathrm{p}=0.18\right.$ ) were found in $\mathrm{FB} 3_{\max }$ between overweight subjects and normal subjects. 
Average FRes max $_{\text {ax }}$ was $723131 \mathrm{~N}(\mathrm{n}=5)$ for overweight subjects, significantly higher $(\mathrm{p}<0.02)$ than $535 \pm 111 \mathrm{~N}(\mathrm{n}=8)$ for normal subjects.

\section{Midsternal compressions}

Time histories of mid-sternal compressions for the overweight group (a) and the normal group (b) are shown in Fig. 5. At an average time of $136 \pm 15 \mathrm{~ms}$, the midsternal compression reached its peak, $\mathrm{C}_{\max }$. There are no significant differences between overweight subjects $\left(B M I \geq 25 \mathrm{~kg} / \mathrm{m}^{2}, \mathrm{n}=5\right)$ and the subjects in the normal group $\left(\mathrm{BMI}<25 \mathrm{~kg} / \mathrm{m}^{2}, \mathrm{n}=8\right)$ in $\mathrm{C}_{\max }$ $(\mathrm{p}=0.41)$.

The pulse applied in the present study is similar to the one applied by Kemper et al. (Kemper et al., 2011) on 5 males volunteers close to 50th percentile submitted to sled test. Average corridor of mid-sternal compressions are compared to those obtained in this study (Kemper et al., 2011) on relaxed subjects $(n=5)$ in Fig. 6 . The average $C_{\max }$ are similar in both studies (7.9\% vs. $8 \%$ ) even if midsternal compressions in the present study rose and dropped slower due to the difference in deceleration pulse characteristics, (4 g, 8 kph vs. $5 \mathrm{~g}, 9.7 \mathrm{kph}$ ).

\section{Force-deflection characteristics}

Fig. 7 shows the relationship between the resultant shoulder belt load FRes and the midsternal deflection D for the normal group (a) and the overweight group (b). The overweight subject thorax was more compliant at the beginning of the loading and FRes increases with deflection continuing on up to $\mathrm{D}_{\max }$. There are no significant differences between overweight subjects $\left(B M I \geq 25 \mathrm{~kg} / \mathrm{m}^{2}, \mathrm{n}=5\right)$ and the subjects in the normal group (BMI $\left.<25 \mathrm{~kg} / \mathrm{m}^{2}, \mathrm{n}=8\right)$ in $\mathrm{D}_{\max }(\mathrm{p}=0.17)$ and as written before, FRes $\mathrm{max}_{\max }$ was significantly higher for the overweight group than for normal group.

The average value of the dynamic stiffness (DS) was $54.8 \pm 15.7 \mathrm{~N} / \mathrm{mm}(\mathrm{n}=13)$, greater than the average value of the effective stiffness (ES), $23.6 \pm 10.1 \mathrm{~N} / \mathrm{mm}(\mathrm{n}=13)$. The different stiffness values are given in Table 2. Average ES was $30.9 \pm 10.6 \mathrm{~N} / \mathrm{mm}(\mathrm{n}=5)$ for overweight 
subjects, significantly higher $(\mathrm{p}<0.02)$ than $19.6 \pm 8.9 \mathrm{~N} / \mathrm{mm}(\mathrm{n}=5)$ for normal group, Fig. 8a. Inversely, average DS was $42.7 \pm 8.71 \mathrm{~N} / \mathrm{mm}(\mathrm{n}=5)$ for the overweight group, significantly lower $(\mathrm{p}<0.05)$ than $61.7 \pm 15.5 \mathrm{~N} / \mathrm{mm}(\mathrm{n}=5)$ for the normal group, Fig. 8b. As only one elderly subject is available in the present study, no assumption can be made about the influence of age on thoracic stiffness.

\section{Discussion}

13 volunteers of different anthropometries, genders and age were submitted to a low deceleration pulse. Thoracic mechanical response quantified using non-invasive techniques was linked to individual characteristics and compared to literature. In particular, the influence of overweight on thoracic mechanical response was evaluated.

Thoracic mechanical responses obtained in the present protocol are similar to those obtained in sled tests (Kemper et al., 2011). The variability of thoracic mechanical response is higher in the present study than in Kemper et al (2011) where only $50^{\text {th }}$ percentile males were considered.

The overweight volunteer group shows significantly higher ES and lower DS than the normal group. Increased compliance due to increased superficial tissue depth may cause the decrease in DS observed for overweight subjects at the beginning of the load. Since no significant difference was observed in $\mathrm{D}_{\max }$ in both group, the FRes $\mathrm{max}_{\max }$ difference due to inertia, should explain consequently the higher ES observed for overweight subjects. Contrary to the trend highlighted by (Forman et al., 2009), no significant difference was found in $\mathrm{C}_{\max }$ for overweight group or for the few obese subjects (BMI $\left.\geq 30 \mathrm{~kg} / \mathrm{m}^{2}, \mathrm{n}=1\right)$ available in the present study.

As FRes $_{\max }$ was also significantly linked to individual characteristics while FB3 $3_{\max }$ not; the implementation of loading direction in the computation of belt force resultant is important. 
Although FRes is a 2D simplified computation, this approximation seems very adequate for the purposes of the current study and is easily reproducible for further studies.

Volunteer experiments overcome limitations related to selection criteria of human surrogates but have to face other challenges such as impact severity far below crash conditions and lower measurement accuracy due to the use of non-invasive techniques. Despite these limitations, this study could help in investigating the role of BMI in thoracic mechanical response variability and in assessing the thoracic mechanical response of a specific population, such the overweight and obese.

To the authors' knowledge, this is the first study to compare thoracic mechanical responses from overweight subjects to normal subjects using frontal sled tests with volunteers. The overweight subjects exhibited significantly greater resultant belt forces, higher effective stiffness and lower dynamic stiffness. Increased soft tissue depth and increased thorax may explain these observed differences.

The recruitment of volunteers has been continued including the elderly. It should allow isolating the influence of age on thoracic mechanical response independently from anthropometrical variations.

\section{Acknowledgements}

The authors would like to acknowledge all the volunteers who participated in this study. The authors would also like to acknowledge Patrick Joffrin, Alain Maupas, Jean-Luc Russo, Sophie Serindat, Loretta Leoni-Duplessy, Dr Georges Baraton for their contribution in the sled tests preparations and the Desgenettes Hospital for providing bone density examinations. In addition, the authors would like to acknowledge Mitsutoshi Masuda from Toyota Motor Corporation for his advice.

\section{Conflict of interest statement}


This study was partly funded by Toyota Motor Europe. S. Compigne is employee of Toyota Motor Europe. 


\section{References}

Abdel-Aziz, Y., Karara, H., 1971. Direct linear transformation from comparator coordinates into object space coordinates in close-range photogrammetry. In Proceedings of the Symposium on Close-Range photogrammetry, Volume 1, pp. 18.

Arbogast, K., Balasubramanian, S., Seacrist, T., Maltese, M., Garcìa-España, J., Hopely, T., Constans, E., Lopez-Valdes, F., Kent, R., Tanji, H., 2009a. Comparison of kinematic responses of the head and spine for children and adults in low-speed frontal sled tests. Stapp Car Crash Journal 53, 329.

Arbogast, K., Nishisaki, A., Balasubramanian, S., Nysaether, J., Niles, D., Sutton, R., Roberts, K., Nadkarni, L., Boulet, J., Maltese, M., 2009b. Expert clinical assessment of thorax stiffness of infants and children during chest compressions. Resuscitation 80(10), 1187-1191. Armstrong, R., Waters, H., and Stapp J., 1968. Human muscular restraint during sled deceleration. SAE International.

Backaitis, S., St-Laurent, A., 1986. Chest deflection characteristics of volunteers and hybrid III dummies. In Proceedings of the 30th Stapp Car Crash Conference, Volume 30, San Diego, California, USA.

Berthet, F., Vezin, P., Cheze, L., Verriest J., 2005. Assessment and analysis of the human rib lateral slopes. Computer Methods in Biomechanics and Biomedical Engineering 8(S1), 3536.

Boulanger, B., Milzman, D., Mitchell, K., Rodriguez, A., 1992. Body habitus as a predictor of injury pattern after blunt trauma. The Journal of Trauma 33(2), 228.

Eickhoff, B., Schrenk, W., Zellmer, H., Meywerk M., 2011. Optimization of seat belt bucke motion for reducing chest deflection, using rib eye sensors. In Proceedings of the 22nd International Technical Conference on the Enhanced Safety of Vehicles (ESV), 11-0098. 
Forman, J., Lopez-Valdes, F., Lessley, D., Kindig, M., Kent, R., Bostrom O., 2009. The effect of obesity on the restraint of automobile occupants. In Annual Proceedings/Association for the Advancement of Automotive Medicine, Volume 53, pp. 25. Association for the Advancement of Automotive Medicine.

Gayzik, F., Yin, M., Danelson, K., Slice, D., Stitzel J., 2008. Quantification of age-related shape change of the human rib cage through geometric morphometrics. Journal of Biomechanics 41(7), 1545 - 1554.

Gutierrez-Fisac, J., Lopez, E., Banegas, J., Graciani, A., Rodriguez-Artalejo F., 2004.

Prevalence of overweight and obesity in elderly people in Spain. Obesity 12(4), 710-715. Jürgens, H., Aune, I., Pieper U., 1990. International data on anthropometry. International Labour Office.

Kemper, A., Beeman, S,. Duma S., 2011. Effects of pre-impact bracing on chest compression of human occupants in low-speed frontal sled tests. SAE Journal (11-0193), 1-6.

Kemper, A., McNally, C., Pullins, C., Freeman, L., Duma, S., Rouhana S., 2007. The biomechanics of human ribs: material and structural properties from dynamic tension and bending tests. Stapp Car Crash Journal 51, 235.

Kent, R., Lee, S., Darvish, K., Wang, S., Poster, C., Lange, A., Brede, C., Lange, D., Matsuoka F., 2005. Structural and material changes in the aging thorax and their role in crash protection for older occupants. Stapp Car Crash Journal 49, 231.

Kent, R., Lessley, D., Sherwood C., 2004. Thoracic response to dynamic, non-impact loading from a hub, distributed belt, diagonal belt, and double diagonal belts. Stapp Car Crash Journal $48,495$.

Klanner, W., 2001. Status report and future development of the Euro NCAP program. In Proceedings of 17th International technical conference on the Enhanced Safety of Vehicles, Amsterdam, Netherlands. 
Krige, D. G., 1951. A statistical approach to some basic mine valuation problems on the Witwatersrand. J. Chem. Metal. Min. Soc. South Africa 52, 119-139.

Kroell, C.K., Schneider, D.C., 1971. Impact tolerance and response of the human thorax. biomechanics of impact injury and injury tolerances of the thorax-shoulder complex. In Proceedings of the 15th Stapp Car Crash Conference.

Lafont, S., Laumon, B., 2003. Vieillissement et gravité des atteintes lésionnelles des victimes d'accident de la circulation routière: Ageing and injury severity among road traffic accident victims. Recherche-Transports-Sécurité 79, 121-133.

Lau, I., Viano, D., 1986. The viscous criterion - bases and applications of an injury severity index for soft tissues, SAE Technical Paper 861882, , doi:10.4271/861882.

Lobdell, T., Kroell, C., Schneider, D., Hering, W., Nahum, A., 1973. Impact response of the human thorax. Human Impact Response Measurement and Simulation, 201-245.

Mertz, H., Horsch, J., Horn, G., Lowne, R., 1991. Hybrid III sternal deflection association with thoracic injury severities of occupants restrained with force limiting belts biomechanics of impact injury and injury tolerances of the thorax-shoulder complex. In SAE PT-92.

Mock, C., Grossman, D., Kaufman, R., Mack, C., Rivara, F., 2002. The relationship between body weight and risk of death and serious injury in motor vehicle crashes. Accident Analysis and Prevention 34(2), 221-228.

Nahum, A., Schneider, D., Kroell, C., 1975. Cadaver skeletal response to blunt thoracic impact, SAE Technical Paper 751150, doi:10.4271/751150.

Ndiaye, A., Chiron, M., 2009. Thorax vulnerability of female car users reported by the road accident field. Rapport Work Package 1., UMRESTTE, 0901. Confidential.

Oskvig, R., 1999. Special problems in the elderly. Chest 115(2), 158S. 
Patrick, L., 1981. Impact force-deflection of the human thorax. In Proceedings of 25th Stapp Car Crash Conference, September 28-30, 1981, Jack Tar Hotel, San Francisco, California, USA.

Poulard, D., Bruyere, K., Compigne, S., Bermond F., 2011. In-vivo test protocol for analysis of thorax response under belt loading. In Proceedings of IRCOBI (International Research Council on the Biomechanics of Injury) Conference, September 14-16, Krakow, Poland. Sandoz, B., Vajda, E., Alonzo, F., Bruyere, K., Bermond F., 2009. Mechanical properties assessment of child trunk. In Proceedings of the XXII Congress of the International Society of Biomechanics., Cape Town, South Africa.

Shaw, G., Lessley, D., Evans, J., Crandall, J., Shin, J., Portier, P., Paolomi, G., 2007. Quasistatic and dynamic thoracic loading tests: cadaveric torsos. In Proceedings of IRCOBI (International Research Council on the Biomechanics of Injury) Conference, September, Maastricht, The Netherlands.

Stalnaker, R., McElhaney, J., Roberts, V., Trollope, M., 1973. Human torso response to blunt trauma. Human Impact Response Measurement and Simulation, 181-199.

Takahashi, H., Frost, H., 1966. Age and sex related changes in the amount of cortex of normal human ribs. Acta Orthopaedica 37(2), 122-130.

Vezin, P., Berthet, F., 2009. Structural characterization of human rib cage behavior under dynamic loading. Stapp Car Crash Journal 53, 93.

Yamada, H., 1970. Strength of Biological Materials. The Williams \& Wikins Company, Baltimore.

Zhou, Q., Rouhana, S., Melvin, J., 1996. Age effects on thoracic injury tolerance. In Proceedings of the 40th Stapp Car Crash Conference, November 4-6, Albuquerque, New Mexico, USA. 


\section{Appendices}

Assessment of methods for the interpolations of mid-sternum landmark trajectory

Two methods were investigated to estimate the missing part of a marker trajectory. First method was a time-based interpolation, based upon cubic interpolation of the anterior and posterior frames available. Second method was a geometrical-based interpolation, based on dual-kriging method (Krige, 1951) using other landmarks available at the same frame.

The two methods were assessed on a known mid-sternum (MS) trajectory during which 30 successive frames were deliberately hidden. The reconstructed MS trajectories were directly used in the computation of mid-sternal deflection. Fig. 9 shows the comparison of the sternal deflections computed from the reference MS trajectory and from the interpolated ones. The second method appeared more suitable since numerous successive frames interpolation could be applied without loss of the deflection peak pattern.

Assessment of FRes as a 2D approximation of the 3D belt force acting on the thorax

FRes provides the resultant force from two known forces with known angle between in a plane. It is a simplified computation of 3D resulting belt force acting on the thorax.

We investigated how the FRes force vector was aligned with the mid sternal deflection (D) vector used to construct the force-deflection curve. Time history of the resulting shoulder belt load FRes projected towards the direction of the mid sternal deflection vector (a) and its contribution to FRes magnitude (b) are shown in Fig. 10. Average contribution of the mid sternal deflection direction to FRes magnitude during the loading (dotted lines) was $94.2 \pm 2.1$ $\%$. The 2D approximation used for FRes appeared very adequate for the purposes of the current study since the obtained FRes force vector was correctly aligned with the mid sternal deflection vector. 


\section{Figure legends:}

Fig. 1. Sled configuration based upon a standard sedan car environment of a front passenger restrained by a 3-point belt.

Fig. 2. Overview of camera location and field of view.

Fig. 3. Computation of the resulting shoulder belt load FRes as defined by (Eickhoff et al., 2011).

Fig. 4. Time history of the seat belt loads, external shoulder belt force $F_{B 3}$ and the resultant shoulder belt force $F_{\text {Res }}$ for normal group (a,c) and overweight group (b,d).

Fig. 5. Time history of midsternal compressions for normal group (a) and overweight group (b).

Fig. 6. Comparison of midsternal compression corridors from the present study and Kemper et al. (2011).

Fig. 7. Force-deflection of thorax volunteers for normal group (a) and overweight group (b).

Fig. 8. Box plots of the effective stiffness (a) and dynamic stiffness (b) in N/mm for normal subjects and overweight subjects.

Fig. 9. Comparison of different methods of interpolations of mid-sternum (MS) landmark trajectory for the computation of mid-sternum deflection.

Fig. 10. Time history of the resulting shoulder belt load FRes projected towards the direction of the mid-sternal deflection vector (a) and its contribution to FRes magnitude (b).

Table 1. Anthropometric characteristics of volunteers.

Table 2. Thoracic mechanical characteristics obtained on volunteers. 
Table 1

\begin{tabular}{|c|c|c|c|c|c|c|}
\hline ID & Gender & $\begin{array}{l}\text { Age } \\
(\text { yo) }\end{array}$ & $\begin{array}{l}\text { Height } \\
(\mathrm{cm})\end{array}$ & $\begin{array}{l}\text { Weight } \\
(\mathrm{kg})\end{array}$ & $\begin{array}{c}\text { BMI } \\
\left(\mathrm{kg} / \mathrm{m}^{2}\right)\end{array}$ & $\begin{array}{l}\text { Midsternal } \\
\text { thickness }(\mathrm{mm})\end{array}$ \\
\hline \multicolumn{7}{|c|}{ Normal subjects } \\
\hline 200 & $\mathrm{~F}$ & 22 & 176 & 58 & 19 & 179 \\
\hline 607 & M & 32 & 164 & 57 & 21 & 223 \\
\hline 862 & $\mathrm{~F}$ & 41 & 161 & 58 & 22 & 224 \\
\hline 806 & M & 21 & 196 & 88 & 23 & 217 \\
\hline 869 & M & 19 & 167 & 64 & 23 & 226 \\
\hline 733 & M & 34 & 198 & 92 & 23 & 233 \\
\hline 957 & $\mathrm{~F}$ & 23 & 155 & 58 & 24 & 187 \\
\hline 225 & M & 32 & 185 & 83 & 24 & 210 \\
\hline Average & - & 28 & 170 & 70 & 22 & 212 \\
\hline$S D$ & - & 8 & 16 & 15 & 2 & 19 \\
\hline \multicolumn{7}{|c|}{ Overweight subjects } \\
\hline 329 & $\mathrm{M}$ & 38 & 173 & 74 & 25 & 213 \\
\hline 948 & M & 25 & 169 & 73 & 26 & 225 \\
\hline 118 & M & 65 & 167 & 74 & 27 & 234 \\
\hline 442 & M & 35 & 176 & 86 & 28 & 258 \\
\hline 370 & $\mathrm{~F}$ & 20 & 173 & 90 & 30 & 219 \\
\hline Average & - & 37 & 172 & 79 & 27 & 230 \\
\hline$S D$ & - & 20 & 4 & 9 & 2 & 17 \\
\hline \multicolumn{7}{|c|}{ All subjects } \\
\hline Average & - & 31 & 174 & 73 & 24 & 219 \\
\hline$S D$ & - & 13 & 13 & 13 & 3 & 20 \\
\hline Min & - & 19 & 155 & 57 & 19 & 179 \\
\hline $\operatorname{Max}$ & - & 65 & 198 & 92 & 30 & 258 \\
\hline
\end{tabular}


Table 2

\begin{tabular}{|c|c|c|c|c|c|c|c|c|}
\hline ID & $\begin{array}{c}\mathrm{FB} 3_{\text {max }} \\
(\mathrm{N})\end{array}$ & $\begin{array}{l}\mathrm{FB} 4_{\text {max }} \\
(\mathrm{N})\end{array}$ & $\begin{array}{c}\text { FRes }_{\text {max }} \\
(\mathrm{N})\end{array}$ & $\alpha_{\text {ini }}\left(^{\circ}\right)$ & $\begin{array}{l}\mathrm{D}_{\max } \\
(\mathrm{mm})\end{array}$ & $\mathrm{C}_{\max }$ & $\begin{array}{c}\mathrm{ES} \\
(\mathrm{N} / \mathrm{mm})\end{array}$ & $\begin{array}{c}\text { DS } \\
(\mathrm{N} / \mathrm{mm})\end{array}$ \\
\hline \multicolumn{9}{|c|}{ Normal subjects } \\
\hline 200 & 560 & 669 & 357 & 156 & 12.5 & 0.07 & 13.3 & 89.4 \\
\hline 607 & 616 & 682 & 417 & 155 & 22.4 & 0.10 & 16.6 & 62.3 \\
\hline 862 & 803 & 860 & 609 & 154 & 12.1 & 0.05 & 28.8 & 59.1 \\
\hline 806 & 986 & 1113 & 526 & 148 & 14.1 & 0.07 & 30.9 & 46.2 \\
\hline 869 & 1036 & 911 & 547 & 153 & 16.5 & 0.07 & 16.0 & 54.4 \\
\hline 733 & 1288 & 1439 & 558 & 156 & 12.9 & 0.06 & 7.3 & 73.1 \\
\hline 957 & 1090 & 1126 & 721 & 151 & 22.5 & 0.12 & 14.3 & 40.9 \\
\hline 225 & 883 & 1023 & 544 & 149 & 10.7 & 0.05 & 30.0 & 68.9 \\
\hline Average & 908 & 978 & 535 & 153 & 15.5 & 0.07 & 19.7 & 61.8 \\
\hline$S D$ & 244 & 255 & 111 & 3.5 & 4.6 & 0.02 & 9.0 & 15.5 \\
\hline \multicolumn{9}{|c|}{ Overweight subjects } \\
\hline 329 & 1045 & 1121 & 602 & 154 & 11.7 & 0.05 & 37.7 & 42.9 \\
\hline 948 & 1092 & 1138 & 821 & 157 & 23.3 & 0.10 & 25.0 & 42.8 \\
\hline 118 & 1067 & 1253 & 726 & 144 & 16.7 & 0.07 & 36.9 & 47.2 \\
\hline 442 & 856 & 930 & 582 & 152 & 26.5 & 0.10 & 15.8 & 31.4 \\
\hline 370 & 1181 & 1588 & 884 & 160 & 19.5 & 0.09 & 33.9 & 54.3 \\
\hline Average & 1048 & 1206 & 723 & 153 & 19.5 & 0.08 & 29.9 & 43.7 \\
\hline$S D$ & 138 & 275 & 131 & 6.9 & 4.3 & 0.01 & 9.5 & 9.6 \\
\hline \multicolumn{9}{|c|}{ All subjects } \\
\hline Average & 962 & 1066 & 607 & 153 & 17.0 & 0.08 & 23.6 & 54.8 \\
\hline$S D$ & 211 & 267 & 149 & 4.2 & 5.3 & 0.02 & 10.1 & 15.7 \\
\hline Min & 560 & 669 & 357 & 144 & 10.7 & 0.05 & 7.3 & 31.4 \\
\hline $\operatorname{Max}$ & 1288 & 1588 & 884 & 160 & 26.5 & 0.12 & 37.7 & 89.4 \\
\hline
\end{tabular}


Fig. 9.

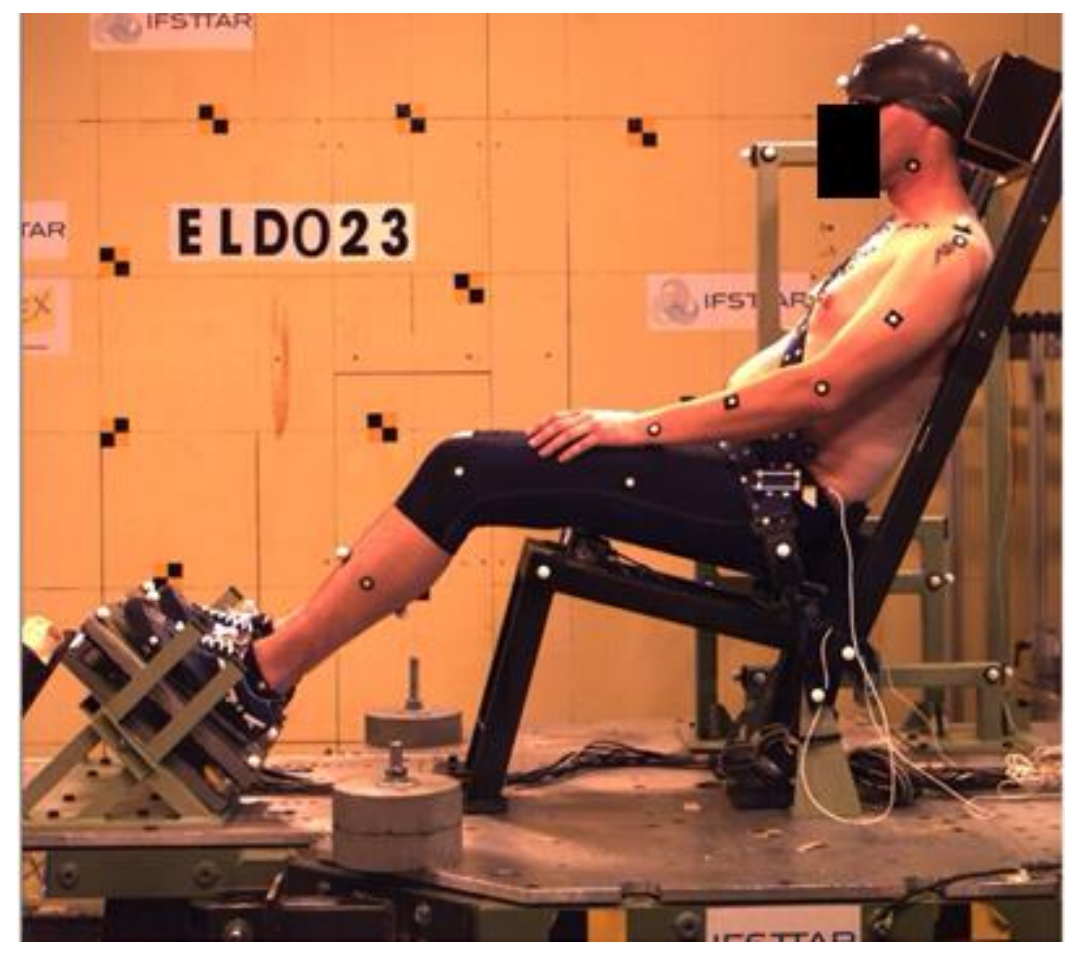


Fig. 10.

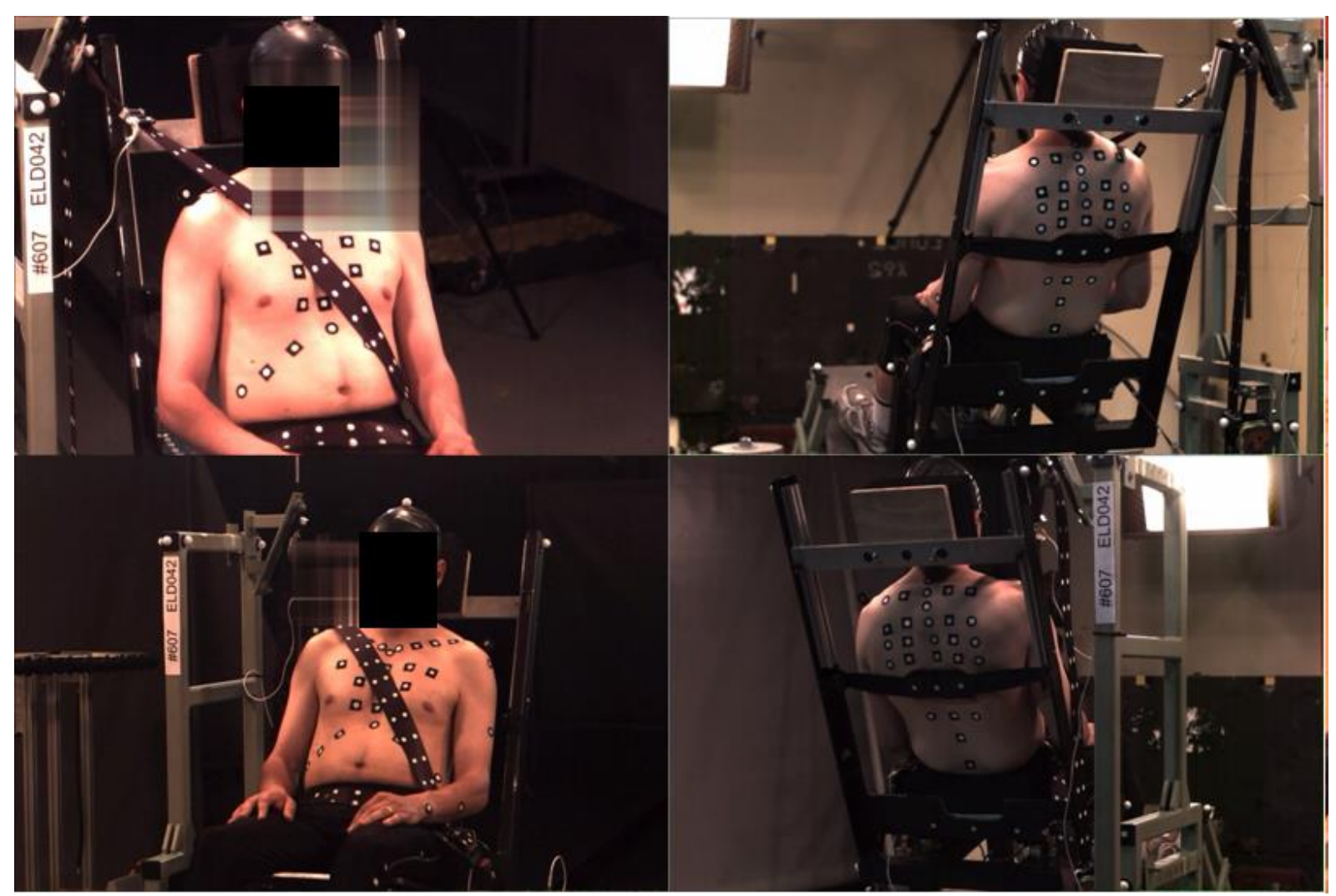


Fig. 11.

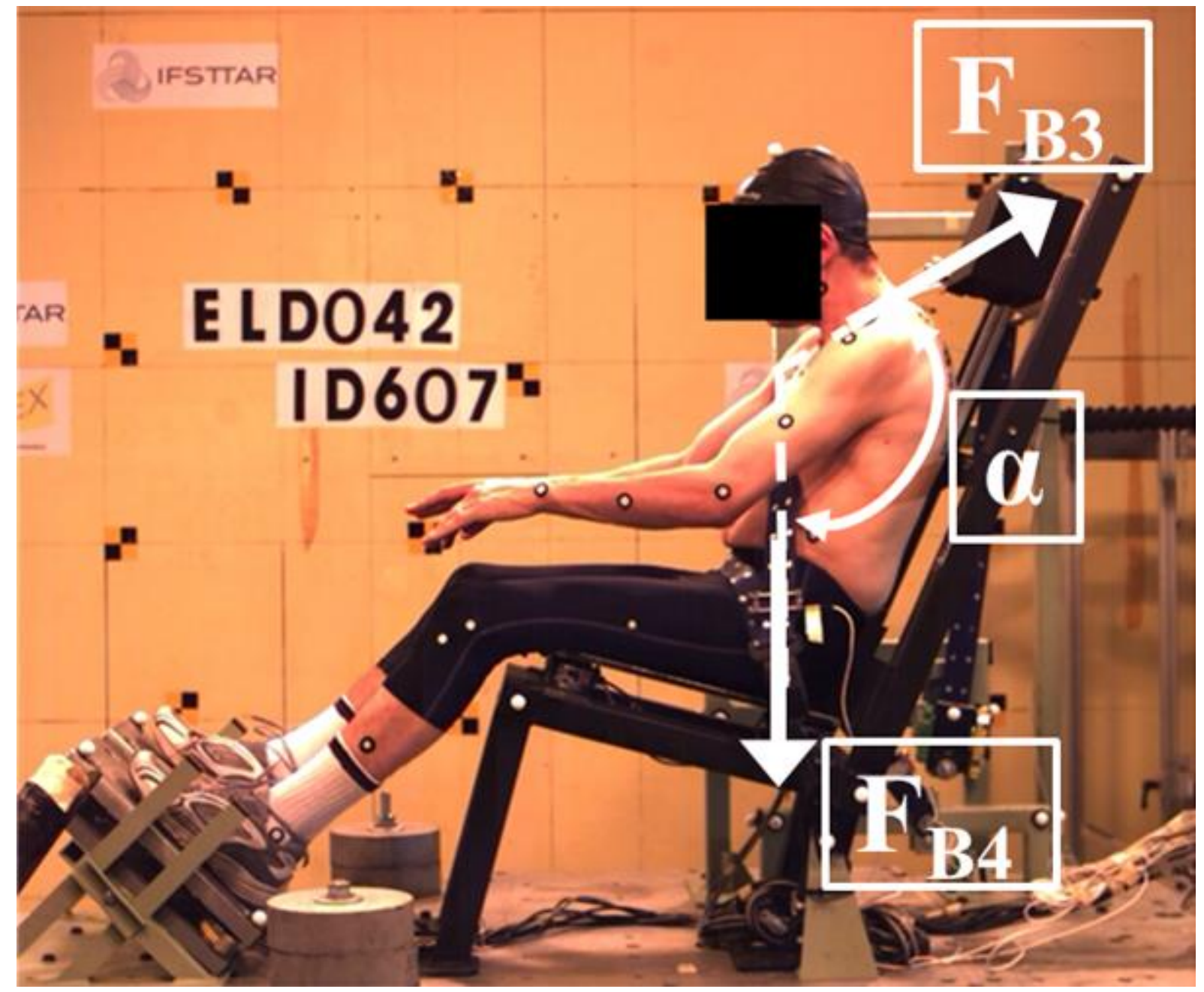


Fig. 12.
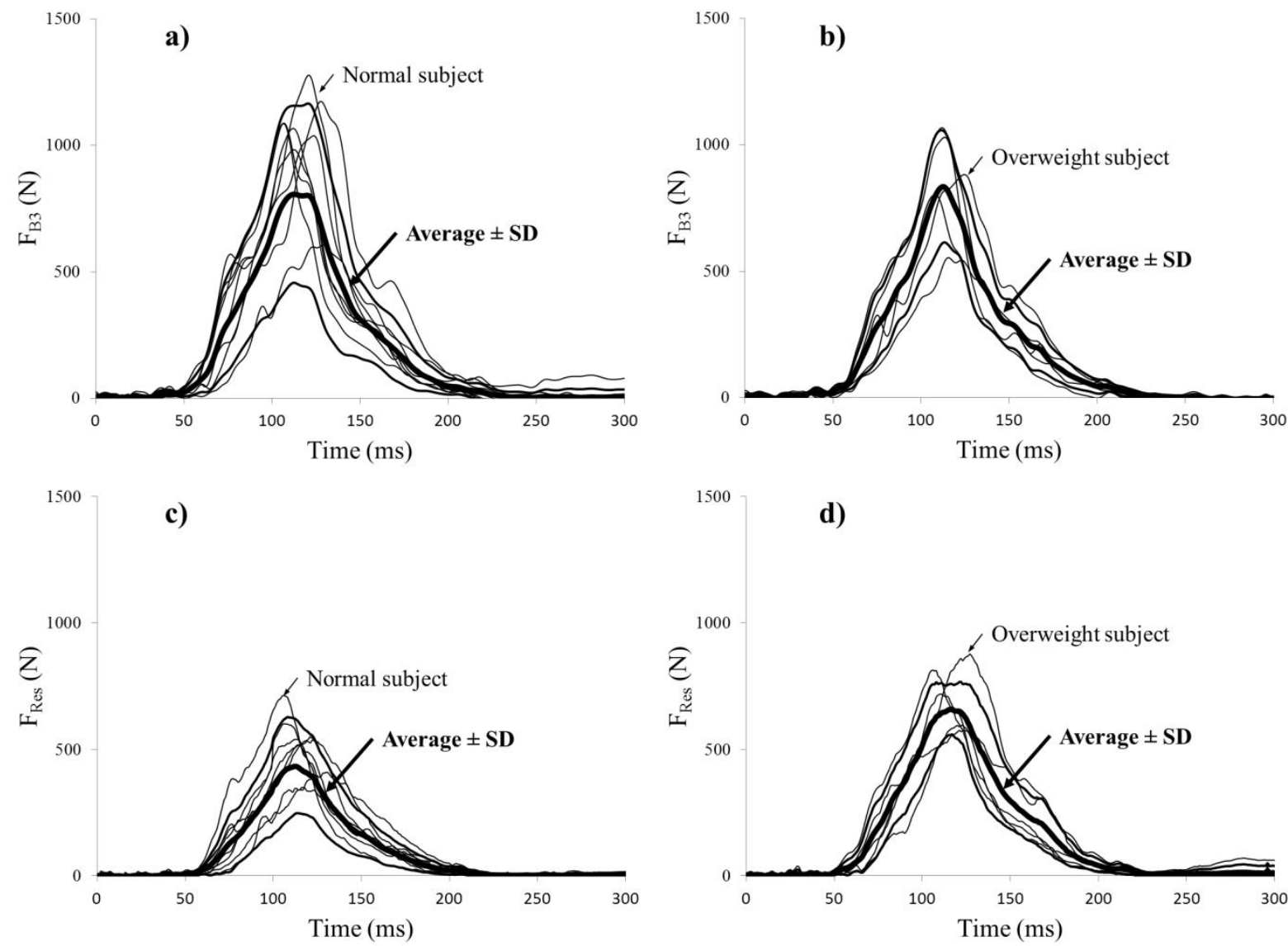
Fig. 13.
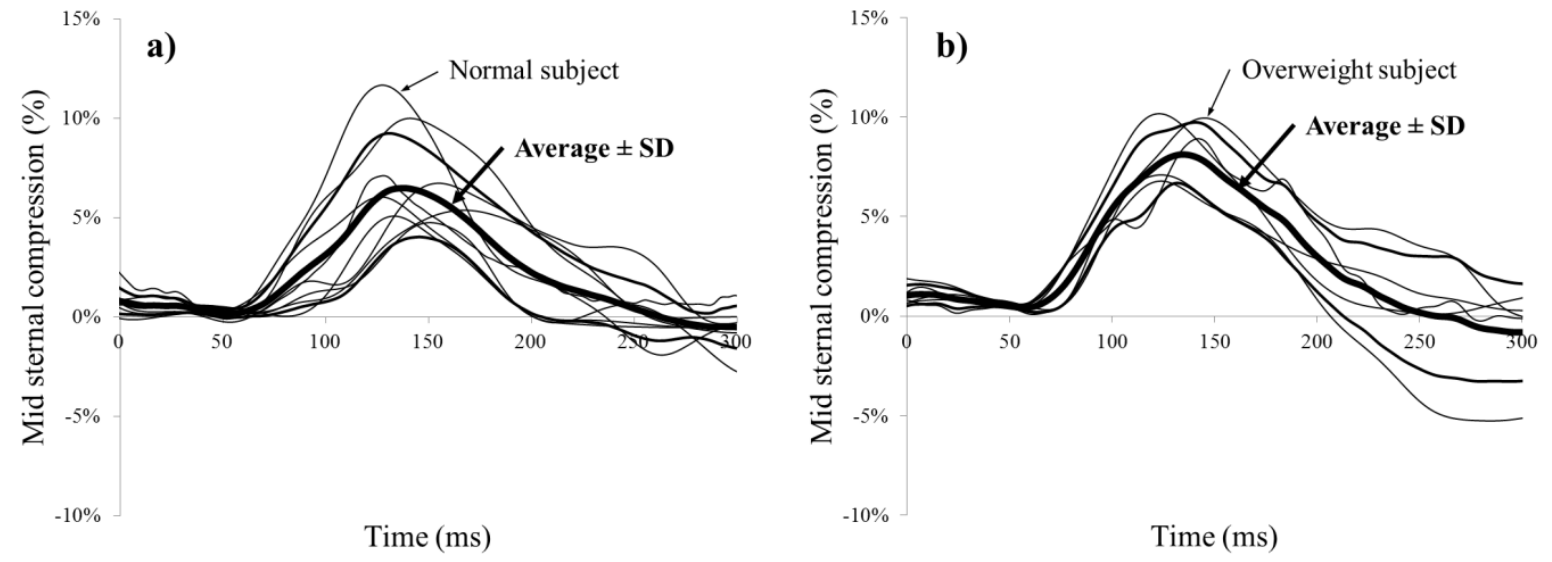
Fig. 14.

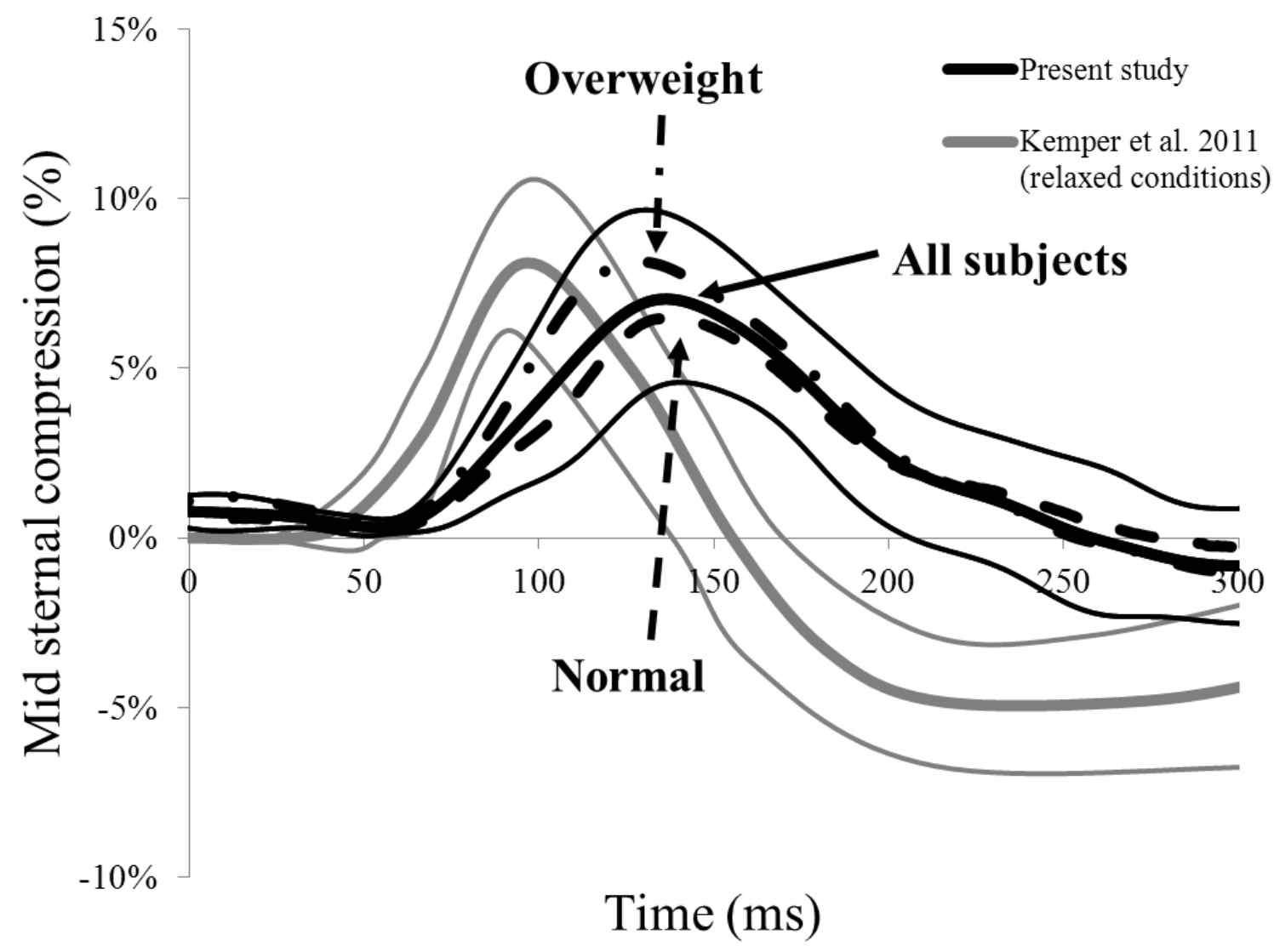


Fig. 15.
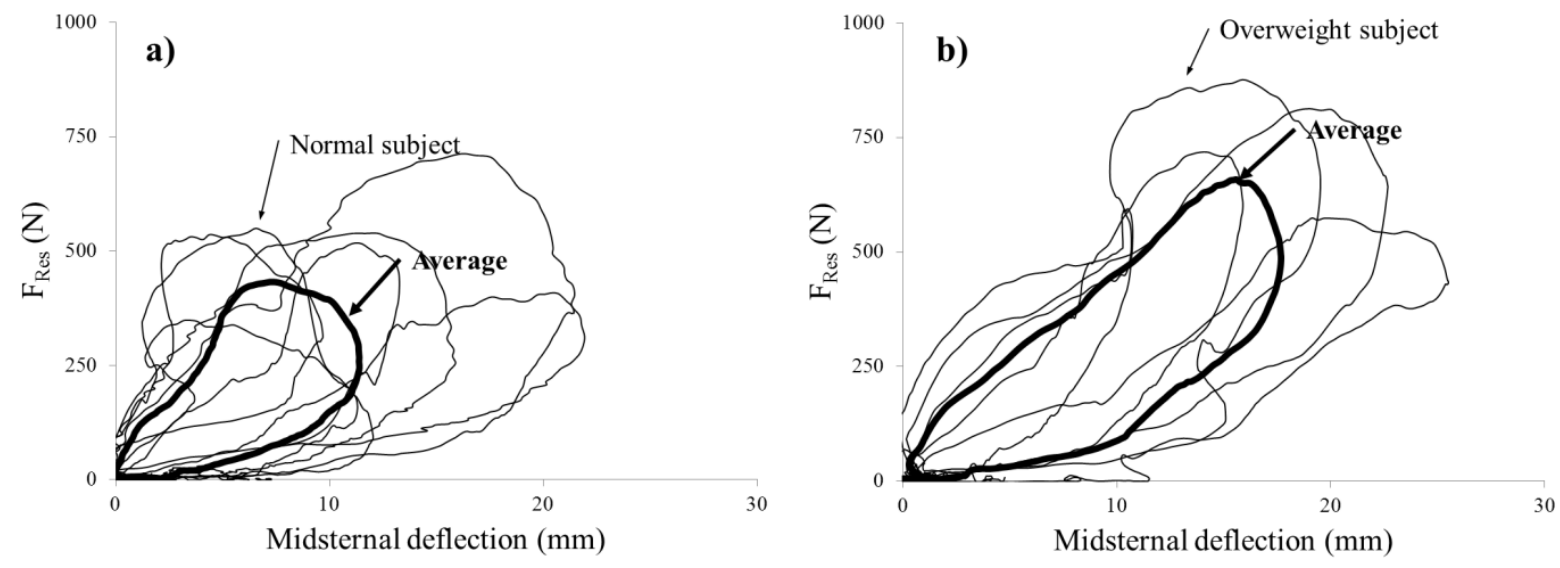
Fig. 16.
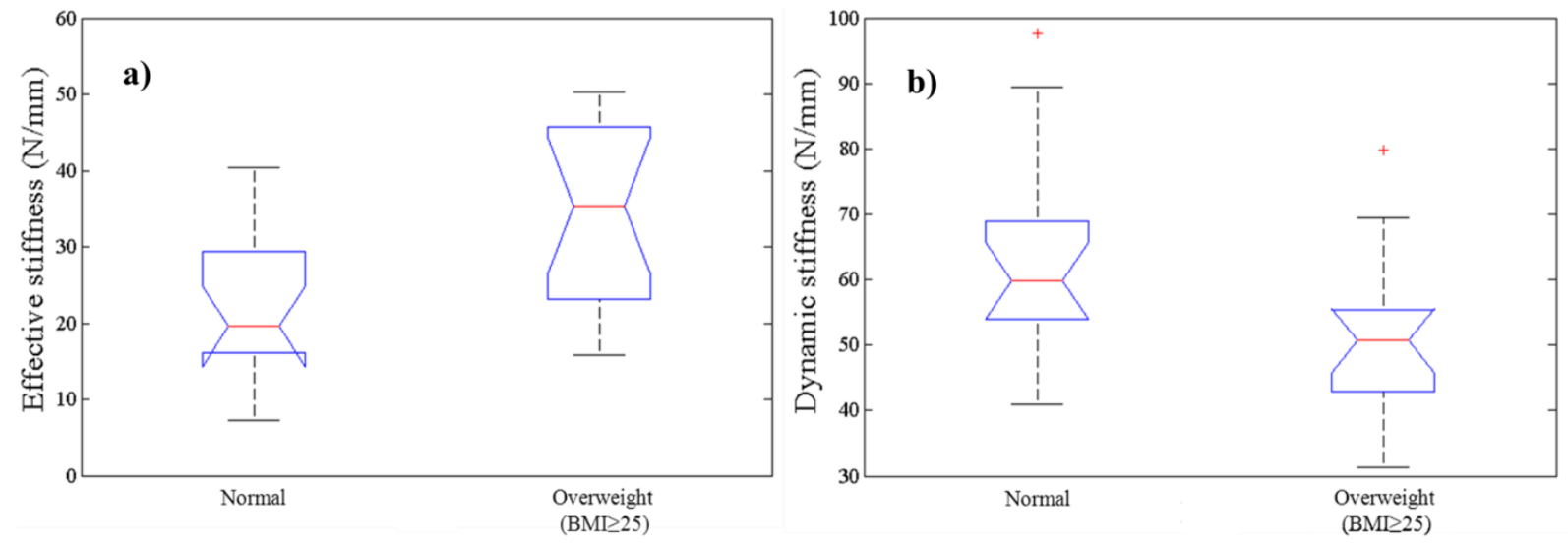
Fig. 17.

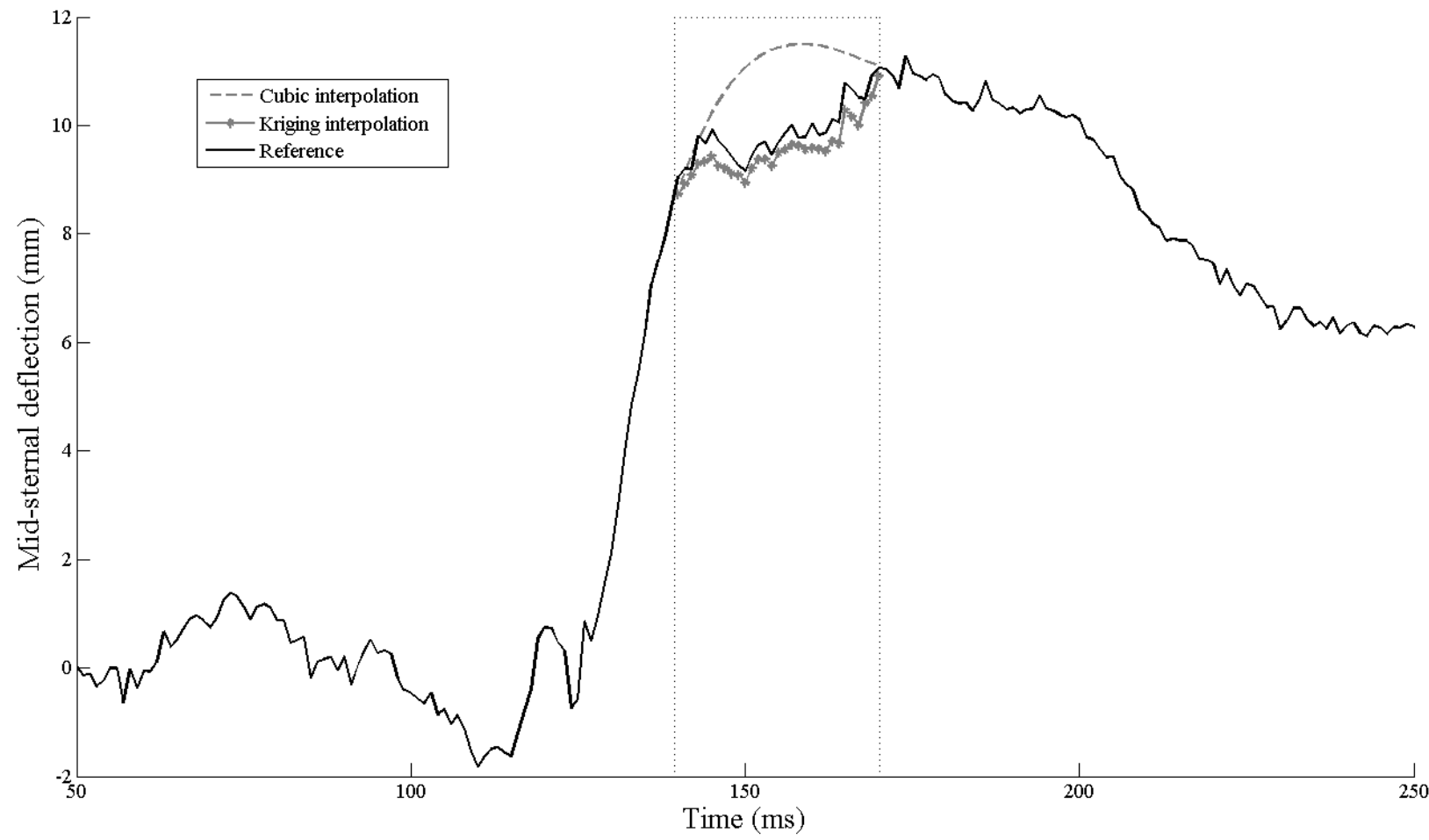


Fig. 18.
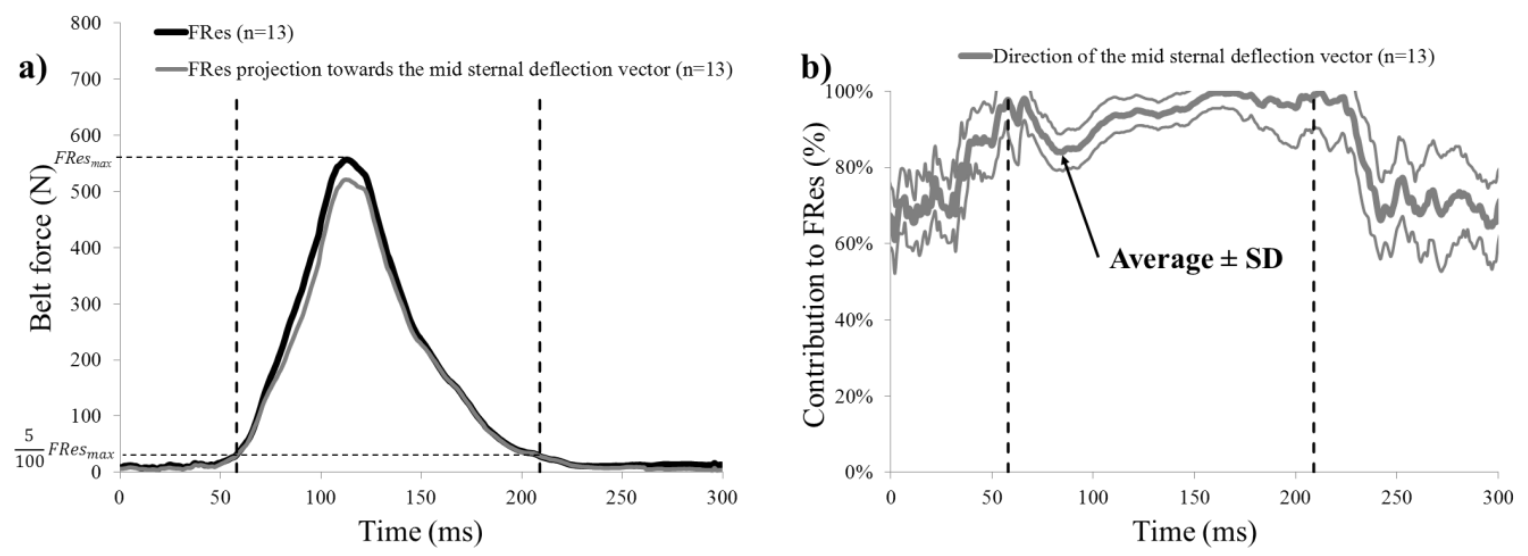